\title{
Ancestral state reconstruction reveals multiple independent evolution of diagnostic morphological characters in the "Higher Oribatida" (Acari), conflicting with current classification schemes
}

Sylvia Schäffer*, Stephan Koblmüller, Tobias Pfingstl, Christian Sturmbauer, Günther Krisper*

\begin{abstract}
Background: The use of molecular genetic data in phylogenetic systematics has revolutionized this field of research in that several taxonomic groupings defined by traditional taxonomic approaches have been rejected by molecular data. The taxonomic classification of the oribatid mite group Circumdehiscentiae ("Higher Oribatida") is largely based on morphological characters and several different classification schemes, all based upon the validity of diagnostic morphological characters, have been proposed by various authors. The aims of this study were to test the appropriateness of the current taxonomic classification schemes for the Circumdehiscentiae and to trace the evolution of the main diagnostic traits (the four nymphal traits scalps, centrodorsal setae, sclerits and wrinkled cuticle plus octotaxic system and pteromorphs both in adults) on the basis of a molecular phylogenetic hypothesis by means of parsimony, likelihood and Bayesian approaches.

Results: The molecular phylogeny based on three nuclear markers (28S rDNA, ef- $1 \alpha$, hsp82) revealed considerable discrepancies to the traditional classification of the five "circumdehiscent" subdivisions, suggesting paraphyly of the three families Scutoverticidae, Ameronothridae, Cymbaeremaeidae and also of the genus Achipteria. Ancestral state reconstructions of six common diagnostic characters and statistical evaluation of alternative phylogenetic hypotheses also partially rejected the current morphology-based classification and suggested multiple convergent evolution (both gain and loss) of some traits, after a period of rapid cladogenesis, rendering several subgroups paraphyletic.

Conclusions: Phylogenetic studies revealed non-monophyly of three families and one genus as a result of a lack of adequate synapomorphic morphological characters, calling for further detailed investigations in a framework of integrative taxonomy. Character histories of six morphological traits indicate that their evolution followed a rather complex pattern of multiple independent gains (and losses). Thus, the observed pattern largely conflicts with current morphological classifications of the Circumdehiscentiae, suggesting that the current taxonomic classification schemes are not appropriate, apart from a recently proposed subdivision into 24 superfamilies.
\end{abstract}

\footnotetext{
* Correspondence: sylvia.schaeffer@uni-graz.at; guenther.krisper@uni-graz.at Institute of Zoology, Karl-Franzens-University Graz, Universitätsplatz 2, 8010 Graz, Austria
} 


\section{Background}

Traditionally, morphological characters are the basis for taxonomy in the animal kingdom. In phylogenetic systematics derived or apomorphic characters are the working tools to reconstruct common ancestors which are further used for the grouping of taxa [1,2]. This concept differs from traditional systematics in that non-phylogenetic classifications are possibly artificial and not useful for asking evolutionary questions [3]. Henning's work was later popularized by the term "cladistics" which focuses on shared derived characters (synapomorphies). With help of these characters, cladistics aims at classifying species into monophyletic groups. Paraphyletic groups are therefore artificial and cannot be used within phylogenetic systematics [3]. Such artificial taxa are results of wrongly used synapomorphic characters caused by homoplastic character evolution and may mislead phylogenetic and taxonomic interpretations. In recent years, morphological analyses were often combined with molecular data to solve a variety of evolutionary and taxonomic problems [4-10]. This rise of combined analyses had an important impact on the nature of systematics [11]. Across many groups of animals, morphology-based classifications have been frequently revised based on new molecular phylogenies by identifying previously undetected homoplastic evolution of morphological characters (e.g. in the flatworm family Capsalidae [12], the genus Dracus [13], the lanternfly family Fulgoridae [14], or in Brazilian worm lizards [15]). Thus, after more than 250 years of predominance of comparative morphology in species discovery and taxonomic classification, future systematic and taxonomic research will, despite some skepticism [16], utilize combined evidence from both molecular and classical taxonomic approaches to enhance our understanding of biological systematics and to serve as basis for answering important questions in evolutionary biology research $[11,17]$.

Traditionally, acarologists have used synapomorphic characters to classify mite species. However, based on this traditional taxonomic approach, phylogenetic relationships among many acarine taxa have remained unclear. Even the monophyly of the Acari is a matter of discussion [18], with two most recent studies providing strong evidence for a diphyly of the Acari $[19,20]$. Also within the two main lineages Anactinotrichida (= Opilioacariformes + Parasitiformes) and Actinotrichida (= Acariformes), some major classificatory changes have been made to reflect current concepts (see [21]). In Actionotrichida for example, recent studies based on either morphological, gland chemical or genetic data strongly indicate that the Astigmata represent a derived monophyletic group within the Oribatida $[19,22,23]$, thus rendering the Oribatida paraphyletic. This case highlights the necessity of combining several analytic approaches to get insights into acarine systematics. Such comprehensive studies combining molecular genetic and morphological data are rare and the few examples are mainly addressing phylogenetic questions on family or genus level $[10,24-26]$. The phylogenetic relationships within the Oribatida are unclear, some studies solely based on molecular data addressed the phylogeography and/or phylogeny of selected taxa only [19,27-30] and very little emphasis has been put on characterizing the evolution of particular traits in a phylogenetic framework. Just one recent study [31] tested whether three particular traits, including two morphological characters, correlate with arboreal life-style in oribatid mites.

This study is the first one to combine morphological and molecular genetic data to elucidate the phylogenetic relationships among the families assigned to the Circumdehiscentiae (= Brachypylina, "Higher Oribatida"), one of the six major groups of Oribatida [32]. The Circumdehiscentiae are the largest and taxonomically richest group of Oribatida, and although several studies aimed at resolving the taxonomy of this group, current taxonomic classifications within the Circumdehiscentiae are considered to be questionable [33]. Many controversial opinions regarding the use of morphological characters for diagnosing circumdehiscent taxa exist, since these characters might be subject to homoplastic evolution, thus not necessarily reflecting the phylogenetic relationships within the Circumdehiscentiae [34]. The first and most cited proposal regarding the systematics of the Circumdehiscentiae was set by Grandjean [35] who defined five subdivisions based on three main characters: i) scalps in nymphs. A scalp is a part of the exuvia of the gastronotic region that is retained on an emerging nymph (or adult in some genera) after the moult. Grandjean called nymphs that retain scalps as eupheredermous; nymphs that do not as apheredermous. In one family (Hermanniellidae) nymphs do not retain scalps but the adults possess the tritonymphal scalp; this characteristic is called opsiopheredermous. One further exception concerns the Oribatellidae: here the species are apopheredermous, with nymphs retaining scalps which are held away from the body by setae. ii) three pairs of centrodorsal setae $d a, d m$ and $d p$; if these setae are lost in nymphs this trait is called dorsodeficient, if setae are present integridorsal. iii) the octotaxic system in adult mites. This system is a special series of originally four pairs of secretory [36] notogastral porose organs (developed as porose areas or saccules) which can vary in size, shape and number. Species featuring the octotaxic system are called poronotic, species without it pycnonotic. Based on these three characters 


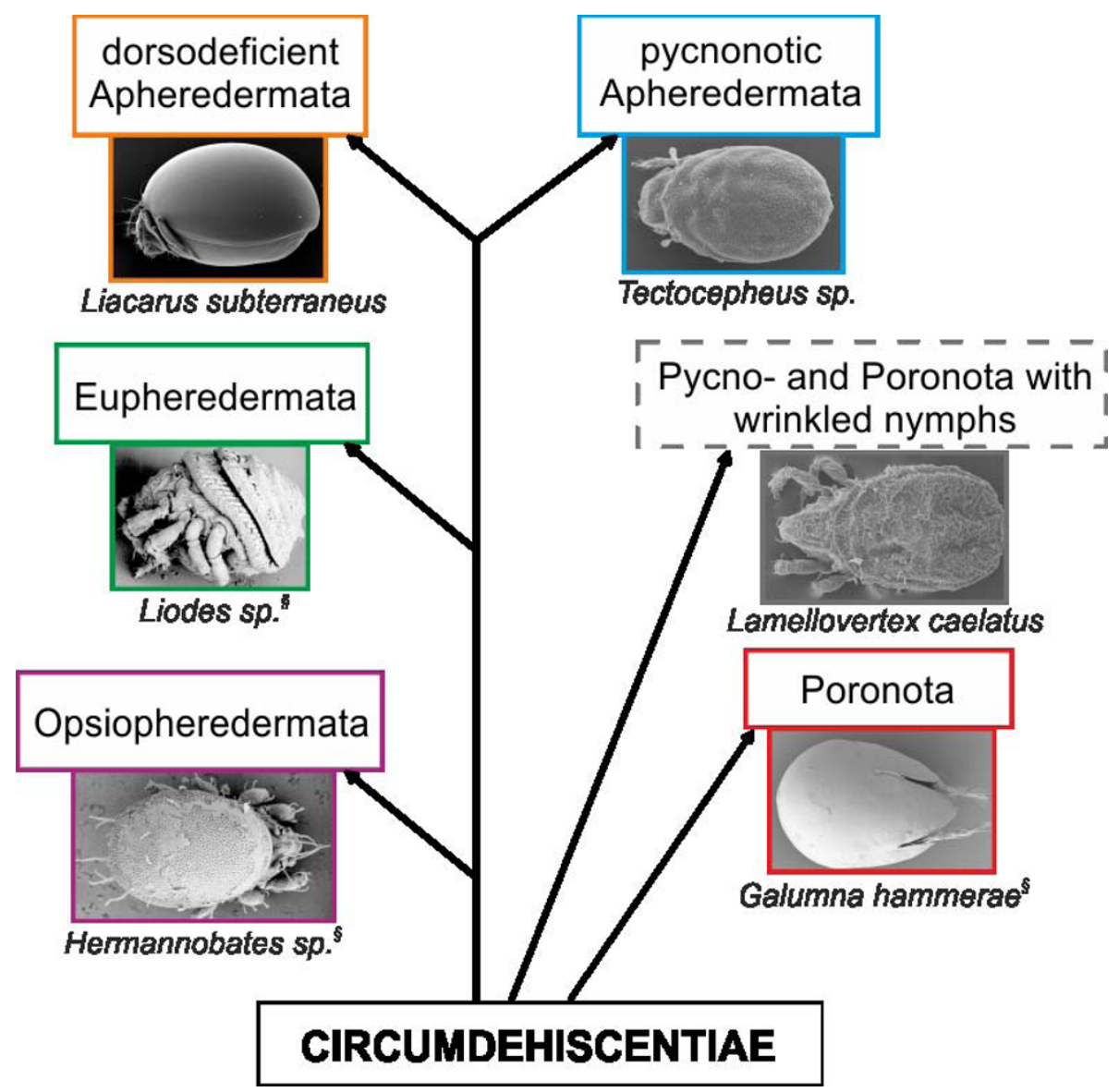

Figure 1 The phylogenetic reconstruction of the Circumdehiscentiae based on 14 morphological characters modified after Wauthy[37]. $\S$ SEM micrographs modified from Hunt et al. [99].

Grandjean defined the five subdivisions Opsiopheredermata, Eupheredermata, dorsodeficient Apheredermata, normal pycnonotic (= integridorsal) Apheredermata and Poronota. Within the Poronota Grandjean [35] formulated three groups according to the appearance of nymphs and larvae (either wrinkled or smooth with micro- or macrosclerits). This classification was also adopted by Wauthy [37] who included a sixth group, the "Circumdehiscentiae (= Pycno- and Poronota) with wrinkled nymphs" to the Circumdehiscentiae, based on ideas of Grandjean [35,38]. In these works, Grandjean assumes that eleven families, including taxa of Eu- and Apheredermata which have nymphs with a wrinkled gastronotic cuticle structure form a monophyletic entity. The phylogenetic relationships among the six subdivisions based on a parsimony analysis of 14 morphological characters are shown in Fig. 1 (modified from Wauthy [37]). Please note that Wauthy's results have never been formally published, but since this study represents the only available cladistic analysis of the Circumdehiscentiae based on morphological characters, we decided to adopt his classification scheme for our analyses. Recent hypotheses mostly avoid Grandjean's old classification scheme. For example, Subías [39] simply classified the Circumdehiscentiae into two groups, the "Pycno- and Poronoticae" and Norton and Behan-Pelletier [34] presented a system without any higher grouping of the taxa, but assigning the circumdehiscent taxa to 24 superfamilies.

To evaluate which of these classifications is the most appropriate one for the Circumdehiscentiae, we inferred a molecular phylogeny and traced several diagnostic morphological characters on the phylogeny. Following Grandjean's [35] classification, we investigated the three main traits (scalps, centrodorsal setae, octotaxic system) plus three additional characters which are also commonly used for categorization: the presence of microand macrosclerits in nymphs, the wrinkled cuticle structure of nymphs, and furthermore the development of so-called pteromorphs in adults. Pteromorphs are humeral projections on the lateral border of the notogaster, concealing all or parts of the adducted legs. In some 
taxa these are immotile structures, whereas in other taxa the base of pteromorphs is de-sclerotized, forming a linear hinge, and inserted with a highly differentiated musculature, allowing for motility of this structure. This trait is known from many poronotic mites and might potentially serve as synapmorphic character within this group.

The aims of the present study are i) evaluating the validity of Grandjean's [35] and Wauthy's [37] taxonomic classification of the Circumdehiscentiae; ii) tracing the evolution of five diagnostic traits (nymphal scalps, centrodorsal setae, sclerits and wrinkled cuticle plus octotaxic system in adults) commonly used for taxonomic classification of circumdehiscent mites; and iii) investigating the potential of pteromorphs for categorization within the Poronota. To achieve our goals, we established a molecular phylogeny based on three nuclear markers, $28 \mathrm{~S}$ ribosomal DNA, elongation factor1 alpha $(e f-1 \alpha)$ and heat shock protein 82 (hsp82), that are commonly used for phylogenetic studies in arthropods [40-44] and in particular for phylogenetic inference in mites, especially in Oribatida [26,27,29,45-47], and traced the evolution of our six morphological traits of interest over the molecular phylogeny using parsimony, likelihood and Bayesian approaches.

\section{Methods}

\section{Sample collection}

This study includes 40 representatives of all five subdivisions of Circumdehiscentiae (after Grandjean [35]): Opsiopheredermata, Eupheredermata, dorsodeficient and pycnonotic Apheredermata and Poronota (Table 1). Families categorized as the sixth subdivision "Circumdehiscentiae with wrinkled nymphs" (after Wauthy [37]) are written in bold lettering in the table. Based on Weigmann [48] we chose Hermannia gibba (Hermanniidae), a member of the Desmonomata, sister group of the Circumdehiscentiae, as outgroup. Sequences not generated in the framework of this study were obtained from GenBank (see Table 1).

Specimens were extracted from mosses, lichens or soil samples with Berlese-Tullgren funnels and preserved in absolute ethanol. Total genomic DNA was extracted from single individuals applying the CTAB (hexadecyltriethylammonium bromide) method described in Schäffer et al. [30]. After DNA extraction, the sclerotized body remnants were mounted on permanent slides and used for species identification using the criteria defined in Weigmann [33].

\section{PCR and DNA sequencing}

Fragments of $28 \mathrm{~S}$ rDNA, $e f-1 \alpha$ and $h s p 82$ genes were amplified by polymerase chain reaction (PCR) using the following primers: D3A and D3B [49] for the D3 fragment of the 28S rDNA, 40.71F and 52.RC [50] and EF-SyFwd and EF-SyRev [10] for ef-1 $\alpha$, hsp1.2 and hsp8. $\mathrm{x}$ [42] for hsp82. Polymerase Chain Reaction (PCR), purification of PCR products and DNA sequencing followed the protocol described in Schäffer et al. [51]. DNA fragments were purified with Sephadex ${ }^{\text {tw }}$ G-50 (Amersham Biosciences) following the manufacturer's instruction and sequencing reaction products were analyzed on an ABI PRISM 3130xl automated sequencer (Applied Biosystems). Sequences are available from GenBank under the accession numbers listed in Table 1.

\section{Alignment and phylogenetic analyses}

We sequenced 311-329 bp of the D3 region of the $28 \mathrm{~S}$ rDNA, 475 bp of the ef-1 $\alpha$, and 467-503 bp of the hsp82 gene in 34 specimens (from Liacarus cf. subterraneus and Arthrodamaeus sp. the fragment of hsp 82 could not be amplified). Sequences were verified by comparisons with known oribatid sequences from GenBank and aligned by eye in MEGA 3.1 [52]. We removed poorly aligned regions from the alignments of $28 \mathrm{~S}$ rDNA and $h s p 82$ using the program trimAl [53] which is a tool for automated alignment trimming. Gap threshold was set to 0.8 and similarity threshold to 0.001 . All sequences were combined into a single data set with a resulting length of $1,298 \mathrm{bp}$ for further analyses.

Phylogenetic inference was based on Bayesian inference (BI), conducted in MrBayes 3.1.2 [54]. Data were partitioned by gene and the $e f-1 \alpha$ gene was further partitioned by codon position. Number of substitution types was set to six (GTR model) for each data partition and among-site rate variation was drawn from a gamma distribution. Posterior probabilities were obtained from a Metropolis-coupled Markov chain Monte Carlo simulation ( 2 independent runs; 4 chains with two million generations each; trees sampled every 100 generations), with parameters estimated from the data set. Mixing and convergence to stationary distributions were evaluated in Tracer v.1.4 by inspecting graphically the trace of the parameter against the generation numbers [55]. The first $4000(20 \%)$ trees were discarded as burn-in prior to constructing a $50 \%$ majority-rule consensus from the remaining 16,001 trees.

\section{Analyses of character evolution}

Ancestral state reconstruction (ASR) is an increasingly popular method to map morphological or ecological traits onto a molecular phylogeny. However, there are still controversial opinions about the accuracy of commonly used methods (maximum parsimony (MP), maximum likelihood (ML), Bayesian) and each suffers from certain advantages and limitations [56-59]. According to Ekman et al. [60], who showed the importance of 
Table 1 Specimens, GenBank accession numbers and coding of morphological characters for the analyzed samples

\begin{tabular}{|c|c|c|c|c|c|c|c|c|c|c|}
\hline \multirow[t]{2}{*}{ Classification } & \multirow[t]{2}{*}{ Species } & \multicolumn{3}{|c|}{ GenBank Accession No. } & \multirow[t]{2}{*}{ sca } & \multirow[t]{2}{*}{ cd } & \multirow[t]{2}{*}{ os } & \multirow[t]{2}{*}{ scl } & \multirow[t]{2}{*}{ gc } & \multirow[t]{2}{*}{ pt } \\
\hline & & $28 \mathrm{~S}$ & ef-1 $\alpha$ & hsp82 & & & & & & \\
\hline \multicolumn{11}{|l|}{ OUTGROUP } \\
\hline \multicolumn{11}{|l|}{ Hermanniidae } \\
\hline \multirow[t]{2}{*}{ Hermannia } & gibba & AY273530 & $\mathrm{EF} 081327^{\mathrm{a}}$ & DQ090800 & 0 & 0 & 0 & 0 & 1 & 0 \\
\hline & gibba & HM582379 & HM582404 & HM582356 & 0 & 0 & 0 & 0 & 1 & 0 \\
\hline \multicolumn{11}{|l|}{ OPSIOPHEREDERMATA } \\
\hline \multicolumn{11}{|l|}{ Hermanniellidae } \\
\hline Hermanniella & punctulata & HM582381 & HM582406 & HM582358 & 1 & 0 & 0 & 0 & 0 & 0 \\
\hline \multicolumn{11}{|l|}{ EUPHEREDERMATA } \\
\hline \multicolumn{11}{|l|}{ Neoliodidae } \\
\hline \multirow[t]{2}{*}{ Platyliodes } & scaliger & HM582376 & HM582401 & HM582353 & 2 & 2 & 0 & 0 & 0 & 0 \\
\hline & $s p$. & HM582375 & HM582400 & HM582352 & 2 & 2 & 0 & 0 & 0 & 0 \\
\hline \multicolumn{11}{|l|}{ Gymnodamaeidae } \\
\hline Arthrodamaeus & $s p$. & HM582387 & HM582412 & - & 2 & 2 & 0 & 0 & 0 & 0 \\
\hline Eutegaeidae & & & & & & & & & & \\
\hline Eutegaeus & curviseta & DQ090816 & $E F 081326^{a}$ & DQ090789a & 2 & 2 & 0 & 0 & 0 & 0 \\
\hline Zetorchestidae & & & & & & & & & & \\
\hline Zetorchestes & falzonii & HM582386 & HM582411 & HM582363 & 2 & 2 & 0 & 0 & 0 & 0 \\
\hline Niphocepheidae & & & & & & & & & & \\
\hline Niphocepheus & nivalis & HM582377 & HM582402 & HM582354 & 2 & 2 & 0 & 0 & 0 & 0 \\
\hline DORSODEFICIENT APHERE & RMATA & & & & & & & & & \\
\hline Liacaridae & & & & & & & & & & \\
\hline Liacarus & cf. subterraneus & HM582389 & HM582413 & - & 2 & 2 & 0 & 0 & 0 & 0 \\
\hline Peloppiidae & & & & & & & & & & \\
\hline Ceratoppia & quadridentata & HM582378 & HM582403 & HM582355 & 2 & 2 & 0 & 0 & 0 & 0 \\
\hline NORMAL PYCNONOTIC AP & REDERMATA & & & & & & & & & \\
\hline Carabodidae & & & & & & & & & & \\
\hline Carabodes & femoralis & AY273508 & $\mathrm{EF} 081325^{\mathrm{a}}$ & DQ090786 ${ }^{\mathrm{a}}$ & 3 & 1 & 0 & 0 & 0 & 0 \\
\hline & labyrinthicus & AY273506 & EF093762 & EF093765 ${ }^{a}$ & 3 & 1 & 0 & 0 & 0 & 0 \\
\hline & marginatus & HM582382 & HM582407 & HM582359 & 3 & 1 & 0 & 0 & 0 & 0 \\
\hline Hydrozetidae & & & & & & & & & & \\
\hline Hydrozetes & lacustris & HM582370 & HM582395 & HM582347 & 3 & 1 & 0 & 0 & 0 & 0 \\
\hline & lemnae & HM582369 & HM582394 & HM582346 & 3 & 1 & 0 & 0 & 0 & 0 \\
\hline Tectocepheidae & & & & & & & & & & \\
\hline Tectocepheus & velatus & EF093757 & EF093763 & EF093770ª & 3 & 1 & 0 & 0 & 1 & 0 \\
\hline & minor & EF093756 & EF093764 & EF093772 & 3 & 1 & 0 & 0 & 1 & 0 \\
\hline & sarekensis & EF093759 & $E F 093760^{a}$ & EF093774 & 3 & 1 & 0 & 0 & 1 & 0 \\
\hline & cf. alatus & HM582383 & HM582408 & HM582360 & 3 & 1 & 0 & 0 & 1 & 0 \\
\hline Ameronothridae & & & & & & & & & & \\
\hline Ameronothrus & maculatus & HM582372 & HM582397 & HM582349 & 3 & 1 & 0 & 0 & 1 & 0 \\
\hline Podacarus & auberti cf. occidentalis & HM582373 & HM582398 & HM582350 & 3 & 1 & 0 & 0 & 1 & 0 \\
\hline Cymbaeremaeidae & & & & & & & & & & \\
\hline Cymbaeremaeus & cymba & GU208575 & GU208670 & HM582340 & 3 & 1 & 0 & 0 & 1 & 0 \\
\hline Scapheremaeus & cf. palustris & HM582371 & HM582396 & HM582348 & 3 & 1 & 0 & 0 & 1 & 0 \\
\hline Ametroproctidae & & & & & & & & & & \\
\hline Ametroproctus & lamellatus & HM582364 & HM582389 & HM582341 & 3 & 1 & 0 & 0 & 1 & 0 \\
\hline PORONOTA & & & & & & & & & & \\
\hline Galumnidae & & & & & & & & & & \\
\hline Galumna & cf. obvia & HM582368 & HM582393 & HM582345 & 3 & 1 & 1 & 2 & 0 & 2 \\
\hline Ceratozetidae & & & & & & & & & & \\
\hline Trichoribates & trimaculatus & HM582384 & HM582409 & HM582361 & 3 & 1 & 1 & 2 & 0 & 1 \\
\hline
\end{tabular}


Table 1 Specimens, GenBank accession numbers and coding of morphological characters for the analyzed samples (Continued)

\begin{tabular}{|c|c|c|c|c|c|c|c|c|c|c|}
\hline \multicolumn{11}{|l|}{ Euzetidae } \\
\hline Euzetes & globulus & HM582374 & HM582399 & HM582351 & 3 & 1 & 1 & 2 & 0 & 1 \\
\hline \multicolumn{11}{|l|}{ Oribatulidae } \\
\hline Phauloppia & cf. lucorum & HM582385 & HM582410 & HM582362 & 3 & 1 & 1 & 1 & 0 & 0 \\
\hline \multicolumn{11}{|l|}{ Scutoverticidae } \\
\hline \multirow[t]{4}{*}{ Scutovertex } & minutus & GU208538 & GU208633 & HM582332 & 3 & 1 & 3 & 0 & 1 & 0 \\
\hline & sculptus & GU208550 & GU208645 & HM582333 & 3 & 1 & 3 & 0 & 1 & 0 \\
\hline & pannonicus & GU208540 & GU208635 & HM582334 & 3 & 1 & 3 & 0 & 1 & 0 \\
\hline & pileatus & GU208544 & GU208639a & HM582336 & 3 & 1 & 3 & 0 & 1 & 0 \\
\hline "Scutovertex" & pictus & GU208541 ${ }^{a}$ & GU208636 & HM582335 & 3 & 1 & 0 & 0 & 1 & 0 \\
\hline Provertex & kuehnelti & GU208567 & GU208662 ${ }^{\mathrm{a}}$ & HM582339 & 3 & 1 & 0 & 0 & 1 & 0 \\
\hline Lamellovertex & caelatus & GU208565 & GU208660 & HM582337 & 3 & 1 & 0 & 0 & 1 & 0 \\
\hline Exochocepheus & hungaricus & GU208570 & GU208665 & HM582338 & 3 & 1 & 3 & 0 & 1 & 0 \\
\hline \multicolumn{11}{|l|}{ Phenopelopidae } \\
\hline Eupelops & cf. curtipilus & HM582380 & HM582405 & HM582357 & 3 & 1 & 1 & 0 & 1 & 2 \\
\hline \multicolumn{11}{|l|}{ Unduloribatidae } \\
\hline Unduloribates & undulatus & HM582365 & HM582390 & HM582342 & 3 & 1 & 0 & 0 & 1 & 1 \\
\hline \multicolumn{11}{|l|}{ Achipteriidae } \\
\hline Parachipteria & punctata & HM582366 & HM582391 & HM582343 & 3 & 1 & 1 & 0 & 1 & 1 \\
\hline \multirow[t]{2}{*}{ Achipteria } & coleoptrata & $\operatorname{AY} 273500^{\mathrm{a}}$ & AY632776 & EF081335 & 3 & 1 & 2 & 0 & 1 & 1 \\
\hline & quadridentata & HM582367 & HM582392 & HM582344 & 3 & 1 & 2 & 0 & 1 & 1 \\
\hline
\end{tabular}

Families written in bold lettering are assigned to the subdivision "Circumdehiscentiae with wrinkled nymphs" after [23]. ${ }^{\text {" }}=$ Sequences obtained from GenBank. Morphological characters and character coding used in this study: sca, scalps ( $0=$ outgroup, $1=$ opsiopheredermous, $2=$ eupheredermous, $3=$ apheredermous); $\mathrm{cd}$, centrodorsal setae $(0=$ holotrich, $1=$ integridorsal, $2=$ dorsodeficient $)$; os, octotaxic system $(0=$ no porose organs, $1=$ porose areas, $2=$ saccules type $1,3=$ saccules type2); scl, sclerits $(0=$ nymphs nude, $1=$ nymphs with microsclerits, $2=$ nymphs with macrosclerits); gc, gastronotic cuticle of nymphs $(0=$ unwrinkled $1=$ wrinkled); pt, pteromorphs $(0=$ no pt, $1=$ pt immotile, $2=$ pt motile).

conducting ASR with more than one method, we performed our analyses using all three above mentioned methods. Furthermore, specifying the right models and priors in a Bayesian analysis is of uttermost importance $[60,61]$. We employed the reversible-jump (RJ) MCMC, where models are visited in proportion to their posterior probability [62].

We traced the evolution of six morphological characters (scalps, centrodorsal setae, sclerits and wrinkled cuticle which are all developed in nymphs plus octotaxic system and pteromorphs both in adults; Table 1) over the molecular phylogeny using MP, ML and Bayesian approaches. Information on the studied characters was retrieved from the literature [33,35,51,63-71] and from the body remnants of our specimens. Ancestral character state reconstruction for the notogastral octotaxic system, employed two different data sets, one (titled porose organs-1) with porose organs (regardless of which type) as either absent (0) or present (1) and one (titled porose organs-2) coded with the different types found in oribatid mites: porose organs absent (0), porose areas (1), saccules type1 (2), saccules type2 (3). With reference to Alberti et al [36] saccules type2 differs from type 1 by lacking an elaborate microvilli system, having a considerable number of mitochondria and rather characteristic lysosome-like inclusions. Parsimony and likelihood based ASR were conducted in Mesquite v.2.71 [72]. To account for topological uncertainty we used the "trace character over trees" option, which summarizes the ASR over a series of trees. All reconstructions were integrated over the last 6001 post burn-in trees of the Bayesian analysis and the ancestral states were summarized on the BI consensus tree. As model of evolution for the ML reconstructions we employed the Markov k-state 1 (Mk1) parameter model, with equal probability for any particular character change. To account for phylogenetic mapping uncertainty, we further evaluated probabilities of ancestral states calculated from the same $6001 \mathrm{BI}$ trees using the MCMC method in BayesMultiState [73], implemented in the BayesTraits 1.0 package. Ancestral states were only reconstructed for 23 nodes (see Fig. 2), which were selected based on their posterior probability support values of the BI analysis (only those nodes with $\mathrm{PP} \geq 0.95$ were used). A reversible-jump (RJ) hyperprior with a gamma prior (exponential prior seeded from a uniform distribution on the interval 0 to 30) was used to reduce uncertainty and arbitrariness of choosing priors in the MCMC analysis. According to preliminary analyses, we set the ratedev value to 8 , achieving an acceptance rate of proposed changes between 20 and 
40\%. The option "AddNode" was used to find the proportion of the likelihood associated with each of the possible states at each node. Three independent MCMC runs were performed with 5,050,000 iterations. Chains were sampled every 100 iteration after a burn-in of 50,000 iterations. Because of similar results of the three runs, we only report one of them here. The output files were analyzed using Tracer v1.4.

\section{Testing alternative hypothesis of character evolution}

Bayes factors (BF) are statistical tools to compare alternative hypotheses against a null hypothesis [74-76]. We used BF to test ten alternative phylogenetic hypotheses against the unconstrained BI tree: Monophyly of i) Apheredermata (hypothesis 1), ii) the dorsodeficient nymphs (hypothesis 2), iii) Poronota (hypothesis 3), iv) nymphs with macrosclerits (hypothesis 4), v) "Circumdehiscentiae with wrinkled nymphs" (hypothesis 5), and vi) pteromorphs (hypothesis 6). Furthermore, we tested the monophyly of the families Scutoverticidae (hypothesis 7), Cymbaeremaeidae (hypothesis 8) and Ameronothridae (hypothesis 9), plus monophyly of each of the three families (hypothesis 10). Alternative phylogenetic trees were inferred in MrBayes by applying topological constraints. Run settings were the same as for the unconstrained BI tree. We combined the two log-files of the Bayesian analysis with the program LogCombiner v1.5.4 available in BEAST package [77] and calculated the BF in Tracer. Standard errors were assessed using 1,000 bootstrap replicates. Interpretation of BF followed Kass and Raftery [76].

\section{Results}

\section{Phylogenetic analysis}

Pairwise sequence divergence (uncorrected p-distances) between the investigated species ranged from $0-11 \%$ in the $\mathrm{D} 3$ fragment of $28 \mathrm{~S} \mathrm{rDNA}$, from $0-22 \%$ in the $e f-1 \alpha$ gene and from $2-26 \%$ in the $h s p 82$ gene. In the combined data set, pairwise differences ranged from 1-20\%.

The Bayesian $50 \%$ majority rule consensus tree is shown in Fig. 2. Most basal nodes were statistically well supported whereas some more recent splits were poorly resolved. Compared to the traditional classification, our BI tree revealed some discrepancies. None of the five or six, respectively, major subdivisions seems to be monophyletic. In particular, the "Eupheredermata", "dorsodeficient Apheredermata" and "Poronota" appeared as paraor polyphyletic. Wauthy's [37] subdivision "Circumdehiscentiae with wrinkled nymphs" clusters together in a major clade, but also includes three species of Poronota (Trichoribates trimaculatus, Euzetes globulus and Galumna cf. obvia), though with low statistical support. The two "circumdehiscent" species Cymbaeremaeus cymba and Ametroproctus lamellatus form a well supported more basal clade, rendering the "Circumdehiscentiae with wrinkled nymphs" paraphyletic. Likewise, the family Scutoverticidae was not resolved as monophylum, but rather constitutes two distinct clusters: one includes exclusively species of the genus Scutovertex, whereas the other one comprises members of the three other genera - Provertex kuehnelti, Lamellovertex caelatus, Exochocepheus hungaricus - plus "Scutovertex pictus" and furthermore Ameronothrus maculatus and Scapheremaeus $c f$. palustris, thus rendering the family paraphyletic. BF of the tested alternative hypothesis rejected a monophyletic family Scutoverticidae (hypothesis 7, Table 2). The aforementioned results also imply paraphyly of the families Cymbaeremaeidae and Ameronothridae supported by the BF which decisively discriminated against a monophyly of the two families (hypotheses 8 and 9, Table 2). Also the monophyly of each of the three families was rejected by the BF (hypothesis 10, Table 2). Moreover, Achipteria coleoptrata clusters with Parachipteria punctata and Achipteria quadridentata as sister taxon, also rendering the genus Achipteria paraphyletic; alternatively, Parachipteria might represent a synonym of Achipteria.

\section{Ancestral state reconstruction}

The results from the ASR of scalps, centrodorsal setae, porose organs, sclerits in nymphs, nymphal cuticle structure and pteromorphs are shown in Figs. 3, 4 and Table 3. The reconstruction yielded no conflicts between parsimony, likelihood and Bayesian analyses except for some nodes, depending on the studied character (Table 3), but the likelihood approach reconstructed them with greater uncertainty (equivocal) than the Bayesian approach. For example, nodes 4 and 5 in scalp evolution (Fig. 3A) or node 17 in data set porose organs-1 (Fig. 3C) were ambiguously reconstructed in the likelihood analysis as compared to the Bayesian analysis (Table 3). On the other hand, the likelihood analysis reconstructed some nodes with greater certainty for a particular character state than the Bayesian approach, as for example nodes 1 and 3 in scalp evolution (Fig. $3 \mathrm{~A}$, Table 3) or node 20 in the reconstruction of gastronotic cuticle structure evolution (Fig. 4B, Table 3).

The reconstruction of character evolution of the nymphal scalps (Fig. 3A) and centrodorsal setae (Fig. 3B) revealed a more or less single origin of the different character states, with the exceptions of the two apheredermous species Ceratoppia quadridentata and Liacarus cf. subterraneus, which clustered together with eupheredermous species, and the eupheredermous Arthrodamaeus sp., which grouped with apheredermous species. The phylogenetic placement of the latter species implies that dorsodeficient nymphs evolved twice. BF of alternative hypotheses reject both the monophyly of 


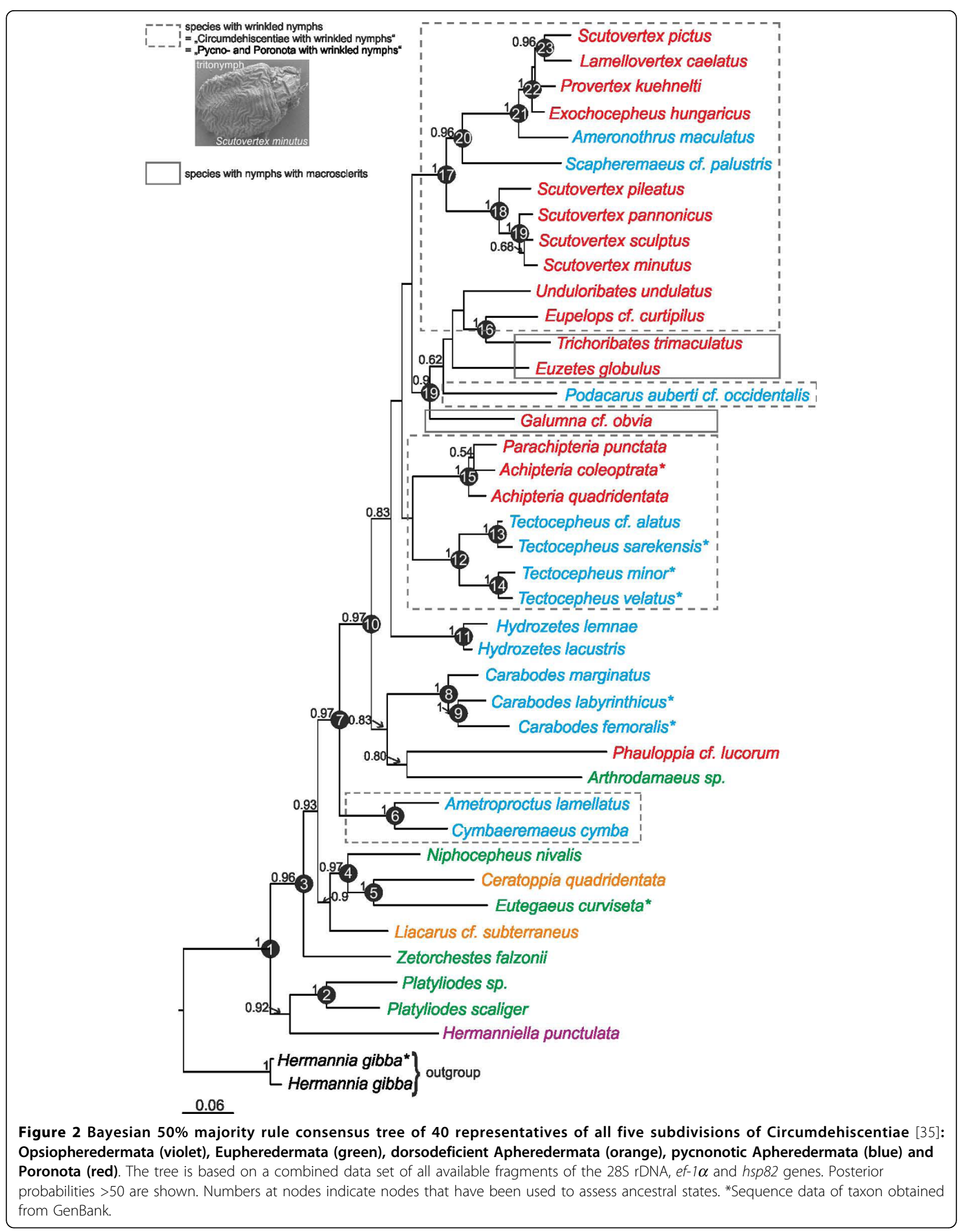


Table 2 Comparison of alternative phylogenetic hypotheses against the unconstrained Bayesian inference (BI) tree using Bayes factors

\begin{tabular}{|c|c|c|c|c|}
\hline Trace & In P (model/data) & Standard error & log10 Bayes Factors & Interpretation Bayes Factors \\
\hline $\mathrm{Bl}$ & $-15019,465$ & $\pm 0,123$ & - & \\
\hline hypothesis 1 & $-15029,989$ & $\pm 0,125$ & $-4,57$ & Decisive \\
\hline $\mathrm{Bl}$ & $-15019,465$ & $\pm 0,125$ & - & \\
\hline hypothesis 2 & $-15065,923$ & $\pm 0,124$ & $-20,176$ & Decisive \\
\hline $\mathrm{Bl}$ & $-15019,465$ & $\pm 0,12$ & - & \\
\hline hypothesis 3 & $-15177,437$ & $\pm 0,112$ & $-68,606$ & Decisive \\
\hline $\mathrm{Bl}$ & $-15019,465$ & $\pm 0,121$ & - & \\
\hline hypothesis 4 & $-15039,901$ & $\pm 0,117$ & $-8,875$ & Decisive \\
\hline $\mathrm{Bl}$ & $-15019,465$ & $\pm 0,117$ & - & \\
\hline hypothesis 5 & $-15113,273$ & $\pm 0,119$ & $-40,74$ & Decisive \\
\hline $\mathrm{Bl}$ & $-15019,465$ & $\pm 0,12$ & - & \\
\hline hypothesis 6 & $-15023,101$ & $\pm 0,125$ & $-1,579$ & Strong \\
\hline $\mathrm{Bl}$ & $-15019,465$ & $\pm 0,12$ & - & \\
\hline hypothesis 7 & $-15091,084$ & $\pm 0,112$ & $-31,104$ & Decisive \\
\hline $\mathrm{Bl}$ & $-15019,465$ & $\pm 0,119$ & - & \\
\hline hypothesis 8 & $-15073,085$ & $\pm 0,121$ & $-23,287$ & Decisive \\
\hline $\mathrm{Bl}$ & $-15019,465$ & $\pm 0,12$ & - & \\
\hline hypothesis 9 & $-15127,044$ & $\pm 0,114$ & $-46,721$ & Decisive \\
\hline $\mathrm{Bl}$ & $-15019,465$ & $\pm 0,122$ & - & \\
\hline hypothesis 10 & $-15197,565$ & $\pm 0,113$ & $-77,348$ & Decisive \\
\hline
\end{tabular}

Apheredermata (hypothesis 1, Table 2) and a monophyletic origin of dorsodeficient nymphs (hypothesis 2, Table 2). The two-state data set of the porose octotaxic organs revealed multiple evolution of this character (Fig. 3C). This agrees with the ASR of the second data set (Fig. 3D; coded with the different types of porose organs) in which porose areas, saccules type 1 and 2 do not share one most recent common ancestor (MRCA). More precisely, saccules type 2 evolved two times and porose areas also at least twice. Particular types of porose organs are typically restricted to one phylogenetic lineage, but with some exceptions. In one family (Achipteriidae), two different types of porose organs are present. Whereas species of the genus Achipteria possess porose areas, the genus Parachipteria has saccules type1, which has been proposed to be the derived form [78]. Results of the ASR of the octotaxic porose organs are supported by BF comparison, which decisively rejected a monophylum Poronota (hypothesis 3, Table 2 ). Ancestral state reconstructions of the development of sclerits in poronotic nymphs indicated multiple independent origin of this trait (Fig. 4A). With Phauloppia cf. lucorum we only had one representative of the character state "nymphs with microsclerits", such that we focused specifically on species showing "nymphs with macrosclerits". According to the reconstruction of Mesquite (Fig. 4A), this trait could have evolved at least two times which is supported by the BF of the tested alternative hypothesis (hypothesis 4 , Table 2). The ASR of the gastronotic cuticle structure of juveniles suggested that wrinkles in nymphs evolved independently at least two to maximum four times (Fig. 4B). Consistent with this observation, $\mathrm{BF}$ comparison rejected the hypothesis enforcing a monophyletic subgroup "Circumdehiscentiae with wrinkled nymphs" (hypothesis 5 , Table 2). The results of the ASR of pteromorphs (Fig. 4C, Table 3) indicated that this structure evolved twice within the Apheredermata and the BF of the alternative hypothesis strongly discriminated against a monophyletic clade of species with pteromorphs. 


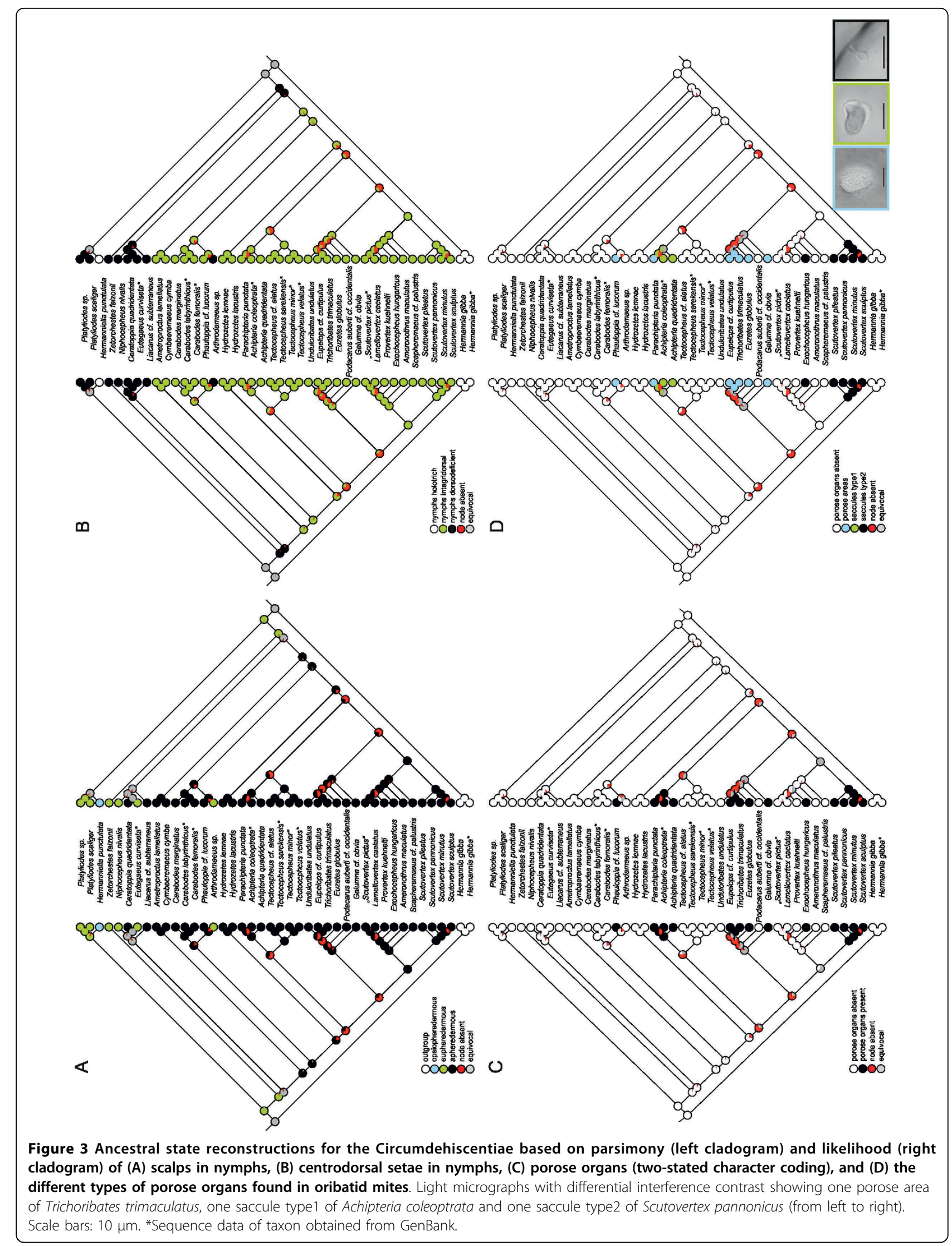




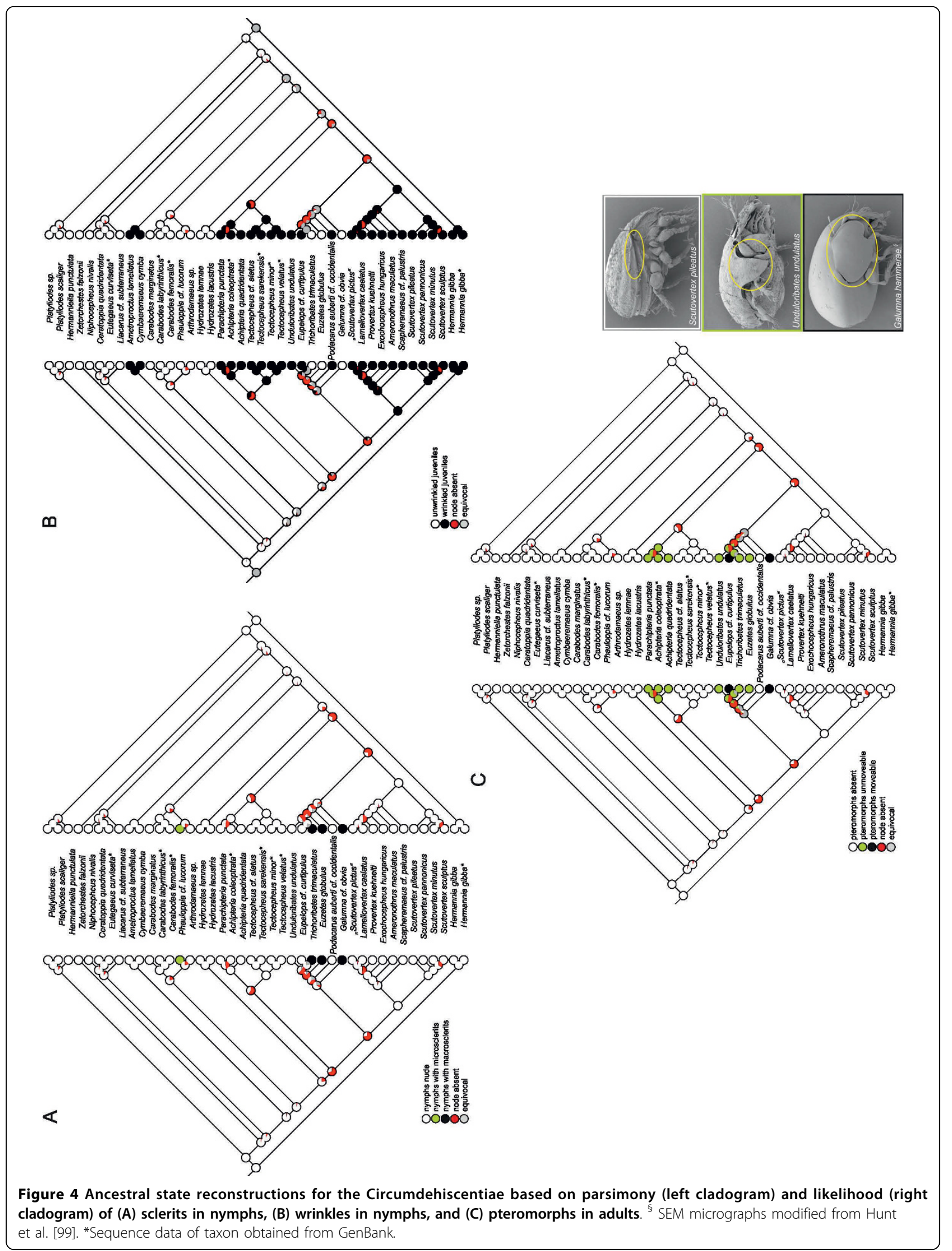


Table 3 Mean of posterior probabilities (PPs) of the Bayesian reconstruction for the ancestral states of six studied characters at 23 nodes from Fig. 2

\begin{tabular}{|c|c|c|c|c|c|c|c|c|c|c|c|c|c|}
\hline \multirow[b]{2}{*}{ node } & \multicolumn{4}{|c|}{ scalps } & \multicolumn{3}{|c|}{ centrodorsal setae } & \multicolumn{2}{|c|}{ porose organ - 1} & \multicolumn{4}{|c|}{ porose organ -2} \\
\hline & 0 & 1 & 2 & 3 & 0 & 1 & 2 & 0 & 1 & 0 & 1 & 2 & 3 \\
\hline 1 & 0.129 & 0.161 & 0.551 & 0.159 & 0.193 & $1.192 \mathrm{E}-2$ & 0.795 & 0.972 & $2.842 \mathrm{E}-2$ & 0.823 & $4.625 \mathrm{E}-2$ & $5.619 \mathrm{E}-2$ & $7.422 \mathrm{E}-2$ \\
\hline 2 & 7.195E-2 & $6.589 \mathrm{E}-2$ & 0.839 & $2.302 \mathrm{E}-2$ & 4.564E-2 & $3.798 \mathrm{E}-3$ & 0.951 & 0.959 & 4.053E-2 & 0.815 & 4.824E-2 & $5.965 \mathrm{E}-2$ & $7.698 \mathrm{E}-2$ \\
\hline 3 & $8.732 \mathrm{E}-2$ & $8.214 \mathrm{E}-2$ & 0.283 & 0.548 & $7.921 \mathrm{E}-2$ & $3.625 \mathrm{E}-2$ & 0.885 & 0.977 & $2.298 \mathrm{E}-2$ & 0.822 & $5.025 \mathrm{E}-2$ & $5.614 \mathrm{E}-2$ & 7.118E-2 \\
\hline 4 & 0.114 & 0.102 & 0.619 & 0.165 & $5.281 \mathrm{E}-2$ & $3.741 \mathrm{E}-3$ & 0.943 & 0.948 & 5.189E-2 & 0.783 & 5.799E-2 & $6.899 \mathrm{E}-2$ & $9.014 \mathrm{E}-2$ \\
\hline 5 & 0.138 & 0.125 & 0.338 & 0.399 & 8.779E-2 & 1.109E-2 & 0.901 & 0.907 & 9.299E-2 & 0.706 & 8.391E-2 & $9.421 \mathrm{E}-2$ & 0.116 \\
\hline 6 & $3.41 \mathrm{E}-2$ & $3.582 \mathrm{E}-2$ & $2.456 \mathrm{E}-2$ & 0.906 & $1.762 \mathrm{E}-2$ & 0.974 & 8.361E-3 & 0.972 & $2.752 \mathrm{E}-2$ & 0.854 & $3.664 \mathrm{E}-2$ & 4.744E-2 & $6.183 \mathrm{E}-2$ \\
\hline 7 & 4.212E-2 & $4.355 E-2$ & $3.752 \mathrm{E}-2$ & 0.877 & 0.186 & 0.573 & 0.241 & 0.936 & $6.441 \mathrm{E}-2$ & 0.638 & 0.114 & 0.129 & 0.12 \\
\hline 8 & $1.541 \mathrm{E}-2$ & $1.75 \mathrm{E}-2$ & $7.441 \mathrm{E}-3$ & 0.96 & $6.358 \mathrm{E}-3$ & 0.992 & $1.756 \mathrm{E}-3$ & 0.992 & $7.518 \mathrm{E}-3$ & 0.933 & $1.491 \mathrm{E}-2$ & $2.171 \mathrm{E}-2$ & $3.002 \mathrm{E}-2$ \\
\hline 9 & 2.793E-2 & $2.776 \mathrm{E}-2$ & $1.686 \mathrm{E}-2$ & 0.927 & $1.411 \mathrm{E}-2$ & 0.981 & $5.184 \mathrm{E}-3$ & 0.982 & 1.764E-2 & 0.89 & $2.761 \mathrm{E}-2$ & $3.477 \mathrm{E}-2$ & 4.764E-2 \\
\hline 10 & 3.423E-2 & $3.736 \mathrm{E}-2$ & $3.452 \mathrm{E}-2$ & 0.894 & 0.173 & 0.648 & 0.178 & 0.861 & 0.139 & 0.525 & 0.163 & 0.179 & 0.134 \\
\hline 11 & 7.894E-3 & $8.032 \mathrm{E}-3$ & $3.046 \mathrm{E}-3$ & 0.981 & $3.285 \mathrm{E}-3$ & 0.996 & 7.709E-4 & 0.997 & 2.789E-3 & 0.973 & $5.943 \mathrm{E}-3$ & $8.732 \mathrm{E}-3$ & 1.209E-2 \\
\hline 12 & 3.029E-2 & $3.006 \mathrm{E}-2$ & $1.842 \mathrm{E}-2$ & 0.921 & $1.524 \mathrm{E}-2$ & 0.979 & $5.591 \mathrm{E}-3$ & 0.981 & 1.927E-2 & 0.88 & 3.016E-2 & $3.778 \mathrm{E}-2$ & $5.183 \mathrm{E}-2$ \\
\hline 13 & 3.394E-3 & $3.491 \mathrm{E}-3$ & $1.068 \mathrm{E}-3$ & 0.992 & $1.259 \mathrm{E}-3$ & 0.998 & $2.525 \mathrm{E}-4$ & 0.999 & 9.317E-4 & 0.99 & $2.211 \mathrm{E}-3$ & $3.451 \mathrm{E}-3$ & 4.733E-3 \\
\hline 14 & $9.165 \mathrm{E}-3$ & $9.32 \mathrm{E}-3$ & $3.52 \mathrm{E}-3$ & 0.978 & 3.799E-3 & 0.995 & 8.827E-4 & 0.997 & $3.238 \mathrm{E}-3$ & 0.969 & $6.899 \mathrm{E}-3$ & $1.013 \mathrm{E}-2$ & $1.398 \mathrm{E}-2$ \\
\hline 15 & 8.217E-3 & $8.786 \mathrm{E}-3$ & $2.644 \mathrm{E}-3$ & 0.98 & $2.728 \mathrm{E}-3$ & 0.997 & 5.34E-4 & $2.432 \mathrm{E}-3$ & 0.998 & 0.97 & $6.732 \mathrm{E}-3$ & $1.016 \mathrm{E}-2$ & 1.351E-2 \\
\hline 16 & 4.279E-2 & $4.315 E-2$ & $3.287 \mathrm{E}-2$ & 0.881 & $2.16 \mathrm{E}-2$ & 0.967 & 1.17E-2 & 4.278E-2 & 0.957 & $1.322 \mathrm{E}-2$ & 0.811 & 0.115 & $6.12 \mathrm{E}-2$ \\
\hline 17 & 3.657E-2 & $3.75 \mathrm{E}-2$ & $2.507 \mathrm{E}-2$ & 0.901 & $1.539 \mathrm{E}-2$ & 0.978 & $6.504 \mathrm{E}-3$ & 0.705 & 0.295 & 0.447 & $6.018 \mathrm{E}-2$ & $9.243 \mathrm{E}-2$ & 0.4 \\
\hline 18 & 1.779E-2 & $1.881 \mathrm{E}-2$ & $9.119 \mathrm{E}-3$ & 0.954 & $7.636 \mathrm{E}-3$ & 0.99 & $2.581 \mathrm{E}-3$ & $1.13 \mathrm{E}-3$ & 0.999 & $5.012 \mathrm{E}-3$ & $1.281 \mathrm{E}-2$ & $2.444 \mathrm{E}-2$ & 0.958 \\
\hline 19 & 4.386E-3 & $4.75 \mathrm{E}-3$ & $1.285 \mathrm{E}-3$ & 0.99 & $1.501 \mathrm{E}-3$ & 0.998 & $2.755 \mathrm{E}-4$ & $1.146 \mathrm{E}-3$ & 0.999 & $3.938 \mathrm{E}-4$ & $2.133 \mathrm{E}-3$ & $4.276 \mathrm{E}-3$ & 0.993 \\
\hline 20 & 5.455E-2 & $5.458 \mathrm{E}-2$ & $4.692 \mathrm{E}-2$ & 0.844 & $3.079 \mathrm{E}-2$ & 0.951 & 1.817E-2 & 0.935 & $6.511 \mathrm{E}-2$ & 0.716 & 6.596E-2 & $7.736 \mathrm{E}-2$ & 0.141 \\
\hline 21 & 1.577E-2 & $1.882 \mathrm{E}-2$ & $8.806 \mathrm{E}-3$ & 0.958 & $7.628 \mathrm{E}-3$ & 0.99 & $2.482 \mathrm{E}-3$ & 0.964 & $3.612 \mathrm{E}-2$ & 0.751 & $2.409 \mathrm{E}-2$ & $3.333 \mathrm{E}-2$ & 0.191 \\
\hline 22 & 4.429E-3 & $5.474 \mathrm{E}-2$ & $1.244 \mathrm{E}-3$ & 0.989 & $1.487 \mathrm{E}-3$ & 0.998 & $1.93 \mathrm{E}-4$ & 0.887 & 0.113 & 0.639 & $1.725 \mathrm{E}-2$ & 2.59E-2 & 0.318 \\
\hline \multirow[t]{2}{*}{23} & 1.679E-2 & $1.884 \mathrm{E}-2$ & 9.5E-3 & 0.955 & $8.235 \mathrm{E}-3$ & 0.989 & $2.654 \mathrm{E}-3$ & 0.991 & 9.344E-3 & 0.933 & 1.609E-2 & $2.144 \mathrm{E}-2$ & $2.975 \mathrm{E}-2$ \\
\hline & \multicolumn{3}{|c|}{ sclerits } & \multicolumn{3}{|c|}{ wrinkles } & \multicolumn{2}{|c|}{ pteromorphs } & & & & & \\
\hline node & 0 & 1 & 2 & 0 & 1 & 0 & 1 & 2 & & & & & \\
\hline 1 & 0.933 & $3.084 \mathrm{E}-2$ & $3.575 \mathrm{E}-2$ & 0.702 & 0.298 & 0.964 & $1.501 \mathrm{E}-2$ & $2.146 \mathrm{E}-2$ & & & & & \\
\hline 2 & 0.927 & $3.285 \mathrm{E}-2$ & $3.984 \mathrm{E}-2$ & 0.944 & $5.638 \mathrm{E}-2$ & 0.953 & $2.034 \mathrm{E}-2$ & 2.687E-2 & & & & & \\
\hline 3 & 0.942 & $2.562 \mathrm{E}-2$ & $3.196 \mathrm{E}-2$ & 0.679 & 0.321 & 0.954 & $1.902 \mathrm{E}-2$ & 2.702E-2 & & & & & \\
\hline 4 & 0.919 & $3.707 \mathrm{E}-2$ & $4.428 \mathrm{E}-2$ & 0.929 & 7.101E-2 & 0.947 & $2.316 \mathrm{E}-2$ & 3.032E-2 & & & & & \\
\hline 5 & 0.89 & $4.856 \mathrm{E}-2$ & $6.167 \mathrm{E}-2$ & 0.871 & 0.129 & 0.91 & 4.249E-2 & 4.722E-2 & & & & & \\
\hline 6 & 0.939 & $2.765 E-2$ & $3.293 \mathrm{E}-2$ & $2.422 \mathrm{E}-2$ & 0.976 & 0.965 & $1.43 \mathrm{E}-2$ & $2.036 \mathrm{E}-2$ & & & & & \\
\hline 7 & 0.92 & 3.53E-2 & $4.471 \mathrm{E}-2$ & 0.214 & 0.786 & 0.888 & $5.379 \mathrm{E}-2$ & $5.85 \mathrm{E}-2$ & & & & & \\
\hline 8 & 0.964 & $1.673 \mathrm{E}-2$ & $1.898 \mathrm{E}-2$ & 0.99 & $9.715 \mathrm{E}-3$ & 0.988 & 4.413E-3 & $8.04 \mathrm{E}-3$ & & & & & \\
\hline 9 & 0.955 & $2.016 \mathrm{E}-2$ & $2.467 \mathrm{E}-2$ & 0.975 & $2.473 \mathrm{E}-2$ & 0.97 & 1.126E-2 & $1.852 \mathrm{E}-2$ & & & & & \\
\hline 10 & 0.904 & $4.18 \mathrm{E}-2$ & $5.375 \mathrm{E}-2$ & 0.445 & 0.555 & 0.843 & $8.328 \mathrm{E}-2$ & 7.343E-2 & & & & & \\
\hline 11 & 0.985 & $6.909 \mathrm{E}-3$ & $8.138 \mathrm{E}-3$ & 0.996 & $3.826 \mathrm{E}-3$ & 0.994 & $2.024 \mathrm{E}-3$ & 4.461E-3 & & & & & \\
\hline 12 & 0.952 & $2.177 \mathrm{E}-2$ & $2.664 \mathrm{E}-2$ & $1.737 \mathrm{E}-2$ & 0.983 & 0.968 & $1.235 \mathrm{E}-2$ & 2.006E-2 & & & & & \\
\hline 13 & 0.993 & $3.313 \mathrm{E}-3$ & $3.835 \mathrm{E}-3$ & 7.777E-4 & 0.999 & 0.998 & $7.118 \mathrm{E}-4$ & $1.772 \mathrm{E}-3$ & & & & & \\
\hline 14 & 0.983 & $8.015 E-3$ & $9.392 \mathrm{E}-3$ & $2.538 \mathrm{E}-3$ & 0.997 & 0.992 & $2.346 \mathrm{E}-3$ & $5.213 \mathrm{E}-3$ & & & & & \\
\hline 15 & 0.981 & $9.517 \mathrm{E}-3$ & $9.287 \mathrm{E}-3$ & $1.672 \mathrm{E}-3$ & 0.998 & $2.801 \mathrm{E}-4$ & 0.988 & 1.144E-2 & & & & & \\
\hline 16 & 0.622 & $5.949 \mathrm{E}-2$ & 0.318 & 0.312 & 0.688 & 8.554E-3 & 0.534 & 0.454 & & & & & \\
\hline 17 & 0.938 & 2.91E-2 & $3.278 \mathrm{E}-2$ & $2.378 \mathrm{E}-2$ & 0.976 & 0.96 & $1.591 \mathrm{E}-2$ & $2.411 \mathrm{E}-2$ & & & & & \\
\hline 18 & 0.967 & $1.627 E-2$ & $1.722 \mathrm{E}-2$ & $6.856 \mathrm{E}-3$ & 0.993 & 0.984 & $5.671 \mathrm{E}-3$ & $1.028 \mathrm{E}-2$ & & & & & \\
\hline 19 & 0.989 & $5.689 \mathrm{E}-3$ & $5.302 \mathrm{E}-3$ & $7.406 \mathrm{E}-4$ & 0.999 & 0.997 & 7.603E-4 & $1.839 \mathrm{E}-3$ & & & & & \\
\hline 20 & 0.915 & $3.907 \mathrm{E}-2$ & $4.572 \mathrm{E}-2$ & 4.787E-2 & 0.952 & 0.936 & $2.884 \mathrm{E}-2$ & $3.511 \mathrm{E}-2$ & & & & & \\
\hline 21 & 0.966 & $1.663 \mathrm{E}-2$ & $1.757 \mathrm{E}-2$ & 6.997E-3 & 0.993 & 0.986 & 5.335E-3 & 8.978E-3 & & & & & \\
\hline 22 & 0.985 & $7.372 \mathrm{E}-3$ & 7.43E-3 & $6.712 \mathrm{E}-4$ & 0.999 & 0.997 & $7.688 \mathrm{E}-4$ & $1.837 \mathrm{E}-3$ & & & & & \\
\hline 23 & 0.965 & $1.696 \mathrm{E}-2$ & $1.809 \mathrm{E}-2$ & 7.417E-3 & 0.993 & 0.984 & $5.782 \mathrm{E}-3$ & $9.748 \mathrm{E}-3$ & & & & & \\
\hline
\end{tabular}

Bold numbers indicate PPs greater than 0.90 


\section{Discussion}

\section{Molecular phylogeny}

Bayesian inference of the phylogeny of the Circumdehiscentiae based on a combined data set of fragments of three nuclear genes revealed a tree topology similar to previous molecular studies $[27,28]$, especially to the most recent phylogeny published by Maraun et al. [31] which is based on the 18S rDNA gene. In the latter study the statistical support for most important nodes is higher than in our case, but we note that taxon sampling differs slightly between Maraun et al.'s and our study. Splits within the Apheredermata are statistically not well supported in our phylogeny, which can be interpreted as a strong indication for a period of rapid cladogenesis at a certain time in the past. Comparing the $18 \mathrm{~S}$ tree with our results in detail revealed a different placement of Scapheremaeus cf. palustris in both phylogenies. Whereas it is grouped with Ameronothrus maculatus and four specimens of the family Scutoverticidae in our phylogeny, it is placed with Eremaeozetes $s p$. as sister taxon to Tectocepheus velatus in the $18 \mathrm{~S}$ tree, but we emphasize that Maraun et al.'s [31] data set did not include any representatives of the Scutoverticidae. Furthermore, our results show that there is no close relationship of A. maculatus and the genus Podacarus auberti cf. occidentalis as already supposed by Grandjean [79]. However, Weigmann and Schulte [80] unified the seven genera of originally three families (Ameronothridae, Podacaridae, Aquanothridae) into one single family Ameronothridae, a system accepted by Norton and Behan-Pelletier [34]. The placement of $S . c f$. palustris and A. maculatus within the Scutoverticidae renders not only this family but also the Cymbaeremaeidae and Ameronothridae paraphyletic. These results could certainly be caused by a strong bias of one single gene. However, the paraphyly of these three families is also supported in our single gene analyses (data not shown). The non-monophyly of Cymbaeremaeidae is also supported by the $18 \mathrm{~S}$ rDNA gene [31] with $S$. palustris and Cymbaeremaeus cymba not clustering together. Whether the family Scutoverticidae should be split up or extended with additional taxa (S. cf. palustris, $A$. maculatus and maybe others) remains unclear until more species of the remaining genera and closely related families (e.g. Ameronothridae, Passalozetidae, Licneremaeidae) are included in a comprehensive phylogenetic study. However, our data, which are certainly not comprehensive enough to allow for a full revision of these problematic families but are sufficient to hint at some taxonomic inconsistencies, indicate that the family Scutoverticidae might be split up in "Scutoverticidae s.s.", so far including only species of Scutovertex and in "Scutoverticidae s.l." with the remaining taxa. The paraphyletic resolution of Ameronothridae, Cymbaeremaeidae and the genus Achipteria appears to be the result of a lack of adequate synapomorphic morphological characters, calling for further detailed investigations not only on a strictly morphological basis, but also including alternative approaches in a framework of integrative taxonomy [11].

\section{Ancestral state reconstruction}

Ancestral state reconstructions and phylogenetic hypothesis testing indicate that none of Grandjean's [35] main traits is a good tool to classify the investigated taxa. However, regarding scalps and centrodorsal setae, the only disagreement to traditional taxonomic classifications is caused by the placement of Arthrodamaeus sp. which clusters within the Apheredermata (Figs. 3AB), supported by BF comparison of alternative phylogenetic hypotheses (Table 2). Reconstruction of the character history of the octotaxic system in adults which is eponymous for the Poronota clearly suggested multiple evolution of this diagnostic character (Figs. 3C-D). The general model of the origin of saccules proposed by Grandjean $[78,81]$ is that porose areas invaginated and formed a saccule having a lumen encircled by porose walls. Thus, porose areas in the octotaxic system would represent the plesiomorphic character state. Concerning the question whether the small porose areas or minute saccules in various Licneremaeoidea (e.g. Licneremaeus, Scutovertex) do either represent a numerical and size regression or the plesiomorphic state of the typical octotaxic system, Norton and Alberti [82] argued that the early evolution of porose organs started small because they are small, even minute in some Licneremaeoidea (a probably paraphyletic assemblage according to [82]) - e. g. Scutoverticidae, Dendroeremaeidae [83] (in our study called saccules type2) -, in their opinion the most earlyderived group of Poronota. According to the numerical regression, it should be mentioned that the octotaxic system is often reduced to one, two or three pairs of organs. Among the Scutoverticidae, for example, no species is known to have the full complement of four pairs, leading to the hypothesis that four pairs do not represent the ancestral state for this family. Norton and Alberti [82] noted that the earliest homologue of the octotaxic system might be a single pair of dermal glands that evolved by gene-duplication or by modification of developmental controls to four pairs. Our results of the ancestral state reconstructions now suggested, that, whatever character coding [either two-stated (Fig. 3C) or organ-type specific (Fig. 3D)] is used, the octotaxic system evolved independently many times in parallel within the Poronota. Furthermore, there are no indications that either porose areas or saccules type 2 are the 
plesiomorphic state of the porose organs as proposed by Grandjean [78,81] and Norton and Alberti [82], respectively. Concerning the weakly supported nodes within the Poronota (Fig. 2), one could hypothesize that porose areas still can be traced back to one MRCA, a hypothesis clearly rejected by our BF comparison of alternative phylogenetic hypotheses (hypothesis 3, Table 2). Saccules type2, present in Scutovertex and Exochocepheus hungaricus, was inferred to have evolved twice from an ancestor lacking porose organs (Fig. 3D). These results reject the general hypothesis that Poronota represent a natural, monophyletic subdivision, as already supposed by Grandjean [38]; he also stated that the presence or absence of these organs alone is not sufficient for a grouping into Pycno- or Poronota. A recent study [34] avoids the terms Pycnonota and Poronota, though it differentiates between pycnonotic and poronotic taxa without implying that these represent monophyletic groupings. Woas [84] suggested that secretory porose organs probably represent functional adaptations, potentially leading to a multiple independent evolution of this morphological character complex. Additionally, it must be noted that in many poronotic families and genera species can have various types of porose organs (see table 1 in [82]). For example, both porose areas and saccules (type1) are found among species of Achipteriidae (Table 1) or Trichoribates [85]. In this regard a potential parallel or convergent evolution of the octotaxic system should already have been a point of discussion in former time. However, considering the complexity of these paired organs located at the more or less same notogastral positions, it appears unlikely that these structures evolved independently multiple times, pointing to the need of further detailed investigations on these structures. Recently, Weigmann [86] reported on a different formation of octotaxic organs on the left and right side of the body of one single specimen and attributed this phenomenon to the differential action of regulatory genes.

In addition to the three main characters, Grandjean [35] used the morphology of nymphs and larvae for a classification within Circumdehiscentiae. He divided the Poronota into three types: 1) species with wrinkled nymphs; 2) species having nymphs with macrosclerits, and 3) species having nymphs with microsclerits. Furthermore, Grandjean [35,38] postulated that those taxa with wrinkled nymphs should form a monophyletic group regardless whether they are pycno- or poronotic (see Background) and that they might represent an intermediate group (he formulated it as "à cheval sur la limite" meaning "at the frontiers") between the pycnonotic Apheredermata and Poronota. This concerns taxa of the following 11 families: Podacaridae, Charassobatidae, Ameronothridae, Scutoverticidae, Tectocepheidae,
Passalozetidae, Cymbaeremaeidae, Licneremaeidae, Achipteriidae, Tegoribatidae and Phenopelopidae (formerly Pelopsidae). Wauthy [37] followed this proposal and named the group "Circumdehiscentiae with wrinkled nymphs". However, our results revealed that the wrinkled nymphal cuticle structure evolved (and got lost) in parallel multiple times among Circumdehiscentiae. This clearly rejects the hypotheses of Grandjean $[35,38]$ and Wauthy [37] that taxa with wrinkled nymphs are monophyletic. Ancestral state reconstructions also showed that the MRCA of Circumdehiscentiae had unwrinkled nymphs (Fig. 4B), thus rejecting the assumption of Norton and Behan-Pelletier [34] that wrinkles in nymphs - because of their occurrence in apheredermous and eupheredermous taxa - seem to be the plesiomorphic or even ancestral state in Circumdehiscentiae.

Pteromorphs only occur (with exception to the eupheredermous Microzetidae) in adult poronotic mites and Travé [87] postulated that the presence or absence of this trait might serve as differentiation criterion within the Apheredermata, a hypothesis rejected by our data (Fig. 4C; Table 2).

\section{Character evolution conflicting with current classification}

Our reconstruction of ancestral states within the Circumdehiscentiae shows that some previously used diagnostic characters are problematic for taxon classification, despite previous efforts to clarify plesioand apomorphies $[86,88]$. These problems mainly arise from the difficulty to evaluate missing characters as reduced or never developed. However, specific traits could be still of appreciable value such as the presence of nymphal scalps or centrodorsal setae. Scalp retention is often correlated with the nature of dehiscence [35], which goes up after a striking process in immature instars. If the metamorphosis fails, for example due to a genetic defect, the molting individual would stall and die. Furthermore, the absence of centrodorsal setae correlates with the scalps [35] because species retaining scalps on their notogaster are dorsodeficient (have lost setae $d a, d m, d p)$. Thus, dorsodeficient nymphs correspond to the Eupheredermata and integridorsal nymphs to the Apheredermata, respectively. As an exception the two dorsodeficient apheredermous families Ceratoppiidae and Liacaridae group with the Eupheredermata with dorsodeficient nymphs, thus suggesting a possible loss of scalps in nymphal stages and adults.

Altogether, none of Grandjean's main traits can be used as diagnostic character for classification of the Circumdehiscentiae, because of clear evidence for multiple parallel evolution (and in some cases also losses) of these traits. In the case of the octotaxic system this could be argued with a possible correlation of secretory 
notogastral porose organs and ecology. Norton and Alberti [82] still noted that poronotic mites with modified porose areas (saccules, multiplications) inhabit nonsoil microhabitats (e.g. mosses and lichens on rocks or trees) and therefore internalization may reduce waterloss through porose surface. But they finally stated that there is no biological or ecological correlation that would help to understand frequent convergent evolution. We hypothesize that maybe there is no correlation of the secretory organs with the present ecology. Considering the old age of Oribatida - the crown radiation of Apheredermata took place at the Triassic/Jurassic boundary (c. 200 MYA) $[19,89]$ or according to Schaefer et al. [90] in the Permian - it might be more adequate to search for congruent environmental conditions in the past, when the explosive radiation within the Apheredermata took place. A monophylum "Circumdehiscentiae with wrinkled nymphs" was clearly rejected by the results of the ancestral state reconstructions, implying that the wrinkled nymphal cuticle structure is of little value for classification. The potential function of these wrinkles was already well studied by Smrž [91] for some oribatid taxa. Thereby he recovered two different types of wrinkling (e.g. Hermannia gibba versus Scutovertex minutus) and a potential correlation between environmental conditions and type of wrinkling.

Typically, studies on character evolution focus on either the potential advantages of a trait in a given environment [92-94] or mechanisms that create novel phenotypes [95,96]. However, Wiens et al. [97] stated that these investigations may be necessary to elucidate why a trait has evolved in a particular instance but not why it has evolved multiple times. According to Wiens et al. [97] at least two additional factors are important in determining the number of origins, namely the biogeographic context of the selective environment and competitive interactions. The first point means that a trait which is adapted to a selective environment may evolve multiple times in geographically isolated regions with identical selective environments (e.g. [98]). We hypothesize that this might be a possible reason for the multiple parallel evolution of the octotaxic system and wrinkled gastronotic cuticle structure in nymphs, but further detailed correlation studies including more taxa are necessary to allow for robust conclusions.

\section{Conclusions}

Ancestral state reconstructions of six diagnostic characters revealed some conflicts to the current morphological classification within the oribatid mite group Circumdehiscentiae. Most of these presumed diagnostic, in particular the octotaxic system (eponymous for the subdivision "Poronota") and the wrinkled gastronotic cuticle of nymphs (taxa having these nymphs were hypothesized to be monophyletic within "poronotic" mites) were inferred to have evolved/been lost multiple times independently, subsequent to an explosive radiation of the "Higher Oribatida" into its major lineages. One likely reason for the parallel or convergent evolution of particular traits might be based on the biogeographic context of the selective environment, meaning that evolution produced similar phenotypes in different geographically isolated habitats [97]. Elucidating the exact (genetic) mechanisms responsible for the observed multiple origin of particular traits and character states remain a task for the future. In particular we want to note that at present we cannot decide whether the genetic basis for these traits evolved several times independently or whether this patchy distribution of traits along a phylogeny is due to atavisms, the preservation of previously existing phenotypic features in the genome, but not expressed in the ancestors. Regardless of the exact mechanism responsible for the observed patterns, the investigated traits do not reflect the phylogenetic relationships among circumdehiscent mites.

Thus, to conclude, the present study clearly shows that the current classification schemes of the Circumdehiscentiae are inappropriate. In our opinion, the most recent proposal by Norton and Behan-Pelletier [34] with 24 superfamilies and no higher groupings best reflects the taxonomic situation/uncertainty within the "Higher Oribatida". However, for future prospects to clarify the taxonomy of the circumdehiscent mites an integrative approach based on various sources of evidence, including molecular data [11], and an increased taxon sampling seems necessary.

\section{Acknowledgements}

Financial support was provided by the Austrian Science Fund (FWF, project number P19544-B16). We are grateful to Ernst Ebermann, Peter Horak, Julia Knapp, Heinrich Schatz and Johan Witters for providing moss samples for our study and Günther Raspotnig for the SEM-micrograph of Liacarus subterraneus. Furthermore, the authors thank Ferdinand Hofer and his team at the Research Institute for electron Microscopy (FELMI) for the cooperation in making SEM-micrographs and four anonymous reviewers for their constructive comments.

\section{Authors' contributions}

SS, TP and GK designed the study. SS performed molecular genetic lab work and together with SK analyses and interpretation of data. TP carried out morphological investigations. SS drafted the manuscript. SK, CS and GK critically revised the manuscript. All authors read and approved the final manuscript.

Received: 8 March 2010 Accepted: 11 August 2010 Published: 11 August 2010

\section{References}

1. Henning W: Grundzüge einer Theorie der phylogenetischen Systematik Berlin: Deutscher Zentralverlag 1950.

2. Henning W: Phylogenetic Systematics Urbana: University of Illinois Press 1966.

3. Wiley EO, Siegel-Causey D, Brooks DR, Funk VA: The Compleat Cladist: A Primer of Phylogenetic Procedures Lawrence, Kansas: University of Kansas Museum of Natural History Press 1991. 
4. Wahlberg N, Braby MF, Brower AVZ, de Jong R, Lee MM, Nylin S, Pierce NE, Sperling FAH, Vila R, Warren AD, Zakharov E: Synergistic effects of combing morphological and molecular data in resolving the phylogeny of butterflies and skippers. Proc R Soc B 2005, 272:1577-1586.

5. Schaap P, Winckler T, Nelson M, Alvarez-Curto E, Elgie B, Hagiwara H, Cavender J, Milano-Curto A, Rozen DE, Dingermann T, Mutzel R, Baldauf S: Molecular phylogeny and evolution of morphology in the social amoebas. Science 2006, 314:661.

6. Schelly R, Salzburger W, Koblmüller S, Duftner N, Sturmbauer C: Phylogenetic relationships of the lamprologine cichlid genus Lepidiolamprologus (Teleostei: Perciformes) based on mitochondrial and nuclear sequences, suggesting introgressive hybridization. Mol Phylogenet Evol 2006, 38:426-438.

7. Petrusek A, Hobæk A, Nilssen JP, Skage M, Černý M, Brede N, Schwenk K: A taxonomic reappraisal of the European Daphnia longispina complex (Crustacea, Cladocera, Anomopoda). Zool Scr 2008, 37:507-519.

8. Harris AJ, Xiang QY, Thomas DT: Phylogeny, origin, and biogeographic history of Aesculus L. (Sapindales) - an update from combined analysis of DNA sequences, morphology, and fossils. Taxon 2009, 58:108-126.

9. Moussalli A, Herbert DG, Stuart-Fox D: A phylogeny of the cannibal snails of southern Africa, genus Natalina sensu lato (Pulmonata: Rhytididae): assessing concordance between morphology and molecular data. $\mathrm{Mol}$ Phylogenet Evol 2009, 52:167-182

10. Schäffer S, Pfingstl T, Koblmüller S, Winkler KA, Sturmbauer C, Krisper G: Phylogenetic analysis of European Scutovertex mites (Acari, Oribatida, Scutoverticidae) reveals paraphyly and cryptic diversity - a molecular genetic and morphological approach. Mol Phylogenet Evol 2010, 55:677-688.

11. Padial JM, Miralles A, De la Riva I, Vences M: The integrative future of taxonomy. Font Zoo 2010, 7:16

12. Perkins EM, Donnellan SC, Bertozzi T, Chisholm LA, Whittington ID: Looks can deceive: Molecular phylogeny of a family of flatworm ectoparasites (Monogenea: Capsalidae) does not reflect current morphological classification. Mol Phylogenet Evol 2009, 52:705-714.

13. Virgilio M, De Meyer M, White IM, Backeljau T: African Dacus (Diptera: Tephritidae): Molecular data and host plant associations do not corroborate morphology based classifications. Mol Phylogenet Evol 2009, 51:531-539.

14. Urban JM, Cryan JR: Entomologically famous, evolutionarily unexplored: the first phylogeny of the lanternfly family Fulgoridae (Insecta: Hemiptera: Fulgoroidea). Mol Phylogenet Evol 2009, 50:471-484.

15. Mott T, Vieites DR: Molecular phylogentics reveals extreme morphological homoplasy in Brazilian worm lizards challenging current taxonomy. Mol Phylogenet Evol 2009, 51:190-200.

16. Valdecasas AG, Williams D, Wheeler QD: 'Integrative taxonomy' then and now: a response to Dayrat (2005). Biol J Linn Soc 2008, 93:211-216.

17. Padial JM, Castroviejo-Fisher S, Kohler J, Vilà C, Chaparro JC, De la Riva I: Deciphering the products of evolution at the species level: the need for an integrative taxonomy. Zool Script 2009, 38:431-447.

18. Dunlop JA, Alberti G: The affinities of mites and ticks: a review. J Zool Syst Evol Res 2008, 46:1-18.

19. Dabert M, Witalinski W, Kazmierski A, Olszanowski Z, Dabert J: Molecular phylogeny of acariform mites (Acari, Arachnida): strong conflict between phylogenetic signal and long-branch attraction artifacts. Mol Phylogenet Evol 2010, 56:222-241.

20. Regier JC, Shultz JW, Zwick A, Hussey A, Ball B, Wetzer R, Martin JW Cunningham $C W$ : Arthropod relationships revealed by phylogenomic analysis of nuclear protein-coding sequences. Nature 2010, 463:1079-1083.

21. Lindquist $\mathrm{EE}$, Krantz GW, Walter DE: Classification. A manual of acarology Texas Tech University PressKrantz GW, Walter DE , 3 2009, 97-103.

22. Norton RA: Morphological evidence for the evolutionary origin of Astigmata (Acari: Acariformes). Exp Appl Acarol 1998, 22:559-594.

23. Sakata $T$, Norton RA: Opisthonotal gland chemistry of early-derivative oribatid mites (Acari) and its relevance to systematic relationships of Astigmata. Int J Acarol 2001, 27:281-292.

24. Navajas M, Gutierrez M, Lagnel J, Boursot P: Mitochondrial cytochrome oxidase I in tetranychid mites: a comparison between molecular phylogeny and changes of morphological and life history traits. Bull Ent Res 1996, 86:407-417.
25. Dabert J, Dabert M, Mironov SV: Phylogeny of Feather Mite Subfamily Avenzoariinae (Acari: Analgoidea: Avenzoariidae) Inferred from Combined Analyses of Molecular and Morphological Data. Mol Phylogenet Evol 2001, 20:124-135.

26. Laumann M, Norton RA, Weigmann G, Scheu S, Maraun M, Heethoff M: Speciation in the parthenogenetic oribatid mite genus Tectocepheus (Acari, Oribatida) as indicated by molecular phylogeny. Pedobiologia 2007, 51:111-122.

27. Maraun M, Heethoff M, Schneider K, Scheu S, Weigmann G, Cianciolo J, Thomas RH, Norton RA: Molecular phylogeny of oribatid mites (Oribatida, Acari): evidence for multiple radiations of parthenogenetic lineages. Exp Appl Acarol 2004, 33:183-201.

28. Domes K, Althammer M, Norton RA, Scheu S, Maraun M: The phylogenetic relationship between Astigmata and Oribatida (Acari) as indicated by molecular markers. Exp Appl Acarol 2007, 42:159-171.

29. Domes K, Norton RA, Maraun M, Scheu S: Reevolution of sexuality breaks Dollo's law. PNAS 2007, 104:7139-7144.

30. Schäffer S, Koblmüller S, Pfingstl T, Sturmbauer C, Krisper G: Contrasting mitochondrial DNA diversity estimates in Austrian Scutovertex minutus and S. sculptus (Acari, Oribatida, Brachypylina, Scutoverticidae). Pedobiologia 2010, 53:203-211.

31. Maraun M, Erdmann G, Schulz G, Norton RA, Scheu S, Domes K: Multiple convergent evolution of arboreal life in oribatid mites indicates the primacy of ecology. P Roy Soc B 2009, 276:3219-3227.

32. Grandjean F: Considérations sur le classement des Oribates. Leur division en 6 groupes majeurs. Acarologia 1969, 11:127-153.

33. Weigmann G: Hornmilben (Oribatida). Die Tierwelt Deutschlands, begründet 1925 von Friedrich Dahl. Teil. Goecke \& Evers: Keltern 2006, 76.

34. Norton RA, Behan-Pelletier VM: Suborder Oribatida. A manual of acarology Texas Tech University PressKrantz GW, Walter DE , 3 2009, 430-564.

35. Grandjean F: Essai de classification des Oribates (Acariens). Bull Soc Zool France 1954, 78:421-446

36. Alberti G, Norton RA, Adis J, Fernandez NA, Kratzmann M, Moreno A, Ribiero E, Weigmann G, Woas S: Porose integumental organs of oribatid mites (Acari, Oribatida): 2. Fine structure. Zoologica 1997, 146:33-114, (Stuttgart).

37. The oribatid mite collection of Prof. J.-C. Lions:[http://www.naturalsciences. be/science/collections/mites/elements/].

38. Grandjean F: Charassobates cavernosus Grandjean 1929 (Acarien, Oribate). Mem Mus nat Hist natur (n.s.), ser. A, Zool 1958, 16:121-140.

39. Subías LS: Listado sistemático, sinonímico y biogeográphico de los ácaros Oribátidos (Acariformes: Oribatida) del mundo. Graellsia 2004, 60:3-305[http://www.ucm.es/info/zoo/Artropodos/Catalogo.pdf], Update 2009.

40. Danforth BN, Sauquet H, Packer L: Phylogeny of the bee genus Halictus (Hypmenoptera: Halictidae) based on parsimony and likelihood analyses of nuclear EF-1 $\alpha$ sequence data. Mol Phylogenet Evol 1999, 13:605-618.

41. Chen B, Butlin RK, Harbach RE: Molecular phylogenetics of the Oriental members of the Myzomyia Series of Anopheles subgenus Cellia (Diptera: Culicidae) inferred from nuclear and mitochondrial DNA sequences. Syst Entomol 2003, 28:57-69.

42. Schön I, Martens K: No slave to sex. Proc R Soc Lond B 2003, 270:827-833.

43. Regier JC, Shultz JW, Ganley ARD, Hussey A, Shi D, Ball B, Zwick A, Stajich JE, Cummings MP, Martin JW, Cunningham CW: Resolving arthropod phylogeny: exploring phylogenetic signal within $41 \mathrm{~kb}$ of protein-coding nuclear gene sequence. Syst Biol 2008, 51:1-19.

44. Ruiz C, Jordal B, Serrano J: Molecular phylogeny of the tribe Sphodrini (Coleoptera: Carabidae) based on mitochondrial and nuclear markers. Mol Phylogenet Evol 2009, 50:44-58.

45. Klompen $\mathrm{H}$ : A preliminary assessment of the utility of elongation factor$1 \alpha$ in elucidating relationships among basal Mesostigmata. Exp App/ Acarol 2000, 24:805-820.

46. Schaefer I, Domes K, Heethoff M, Schneider K, Schoen I, Norton RA, Scheu S, Maraun M: No evidence for the 'Meselson effect' in parthenogenetic oribatid mites (Acari, Oribatida). J Evol Biol 2006, 19:184-193.

47. Klimov PB, OConnor BM: Origin and higher-level relationships of psoroptidian mites (Acari: Astigmata: Psoroptidia): evidence from three nuclear genes. Mol Phylogenet Evol 2008, 47:1135-1156.

48. Weigmann G: Hypostome morphology of Malaconothroidea and phylogenetic conclusions on primitive Oribatida. Acarology IX - 
Proceedings, Vol. 1 Ohio: Biological Survey, Columbus, OhioMitchell R, Horn DJ, Needham GR, Welbourn WC 1996, 273-276.

49. Litvaitis MK, Nunn G, Thomas WK, Kocher TD: A molecular approach for the identification of meiofaunal turbellarians (Platyhelminthes, Turbellaria). Mar Biol 1994, 120:437-442.

50. Regier JC, Shultz JW: Molecular phylogeny of the major arthropod groups indicates polyphyly of crustaceans and a new hypothesis for the origin of hexapods. Mol Biol Evol 1997, 14:902-913.

51. Schäffer S, Krisper G, Pfingstl T, Sturmbauer C: Description of Scutovertex pileatus sp. nov. (Acari, Oribatida, Scutoverticidae) and molecular phylogenetic investigation of congeneric species in Austria. Zool Anz 2008, 247:249-258

52. Kumar S, Tamura K, Nei M: MEGA3: integrated software for molecular evolutionary genetics analysis and sequence alignment. Brief. Bioinform 2004, 5:150-163.

53. Capella-Gutiérrez S, Silla-Martínez JM, Gabaldón T: TrimAl: a tool for automated alignment trimming in large-scale phylogenetic analyses. Bioinformatics 2009, 25:1972-1973.

54. Ronquist F, Huelsenbeck JP: MrBayes 3: Bayesian phylogenetic inference under mixed models. Bioinformatics 2003, 19:1572-1574.

55. Rambaut A, Drummond AJ: Tracer v1.4. 2007 [http://beast.bio.ed.ac.uk/ Tracer].

56. Cunningham CW, Omland KE, Oakley TH: Reconstructing ancestral character states: a critical reappraisal. Trends Ecol Evol 1998, 13:361-366.

57. Cunningham CW: Some limitations of ancestral character-state reconstruction when testing evolutionary hypotheses. Syst Biol 1999, 48:665-674.

58. Ronquist F: Bayesian inference of character evolution. Trends Ecol Evol 2004, 19:475-481.

59. Vanderpoorten A, Goffinet B: Mapping uncertainty and phylogenetic uncertainty in ancestral character state reconstruction: an example in the moss genus Brachytheciastrum. Syst Biol 2006, 55:957-971.

60. Ekman S, Andersen HL, Wedin M: The limitations of ancestral state reconstruction and the evolution of the ascus in the Lecanorales (lichenised Ascomycota). Syst Biol 2008, 57:141-156.

61. Couvreur TLP, Gort G, Richardson JE, Sosef MSM, Chatrou LW: Insights into the influence of priors in posterior mapping of discrete morphological characters: a case study in Annonaceae. PLoS One 2010, 5:e10473.

62. Pagel M, Meade A: Bayesian analysis of correlated evolution of discrete characters by reversible-jump Markov chain Monte Carlo. Am Nat 2006, 167:808-825

63. Kunst M: Bulgarische Oribatiden (Acarina) III. Acta Univ Carolinae Biol 1959, 6:51-74.

64. Hammer M: Investigations on the oribatid fauna of New Zealand, Part I. Biol Skr Dan Vid Selsk 1966, 15:1-108.

65. Wallwork JA: Some Cryptostigmata (Acari) from South Georgia. Br Antarct Surv Bull 1966, 9:1-20.

66. Behan-Pelletier VM: Redefinition of Ametroproctus (Acari: Oribatida) with descriptions of new species. Can Ent 1987, 119:505-536.

67. Ermilov SG: The life cycle of Hydrozetes lemnae (Oribatei, Hydrozetidae). Zool Zh 2006, 85:853-858.

68. Seniczak S, Solhøy T, Seniczak A: Systematic status of Hydrozetes octosetosus Willmann, 1932 (Acari: Oribatida: Hydrozetidae) in the light of ontogenetic and ecological studies. J Nat Hist 2007, 41:2081-2098.

69. Schäffer S, Krisper G: Morphological analysis of the adult and juvenile instars of Scutovertex minutus (Acari, Oribatida, Scutoverticidae). Rev Suisse Zool 2007, 114:663-683.

70. Pfingstl T, Schäffer S, Ebermann E, Krisper G: Intraspecific morphological variation of Scutovertex sculptus Michael (Acari: Oribatida: Scutoverticidae) and description of its juvenile stages. Zootaxa 2008, 1829:31-51.

71. Pfingstl T, Schäffer S, Krisper G: Re-evaluation of the synonymy of Latovertex Mahunka, 1987 and Exochochepheus Woolley \& Higgens, 1968 (Acari, Oribatida, Scutoverticidae). Int J Acarol .

72. Maddison WP, Maddison DR: Mesquite: a modular system for evolutionary analysis. Version 2.71. 2009 [http://mesquiteproject.org.]

73. Pagel M, Meade A, Barker D: Bayesian estimation of ancestral character states on phylogenies. Syst Biol 2004, 53:673-684.

74. Jeffreys $\mathrm{H}$ : Some tests of significance, treated by the theory of probability. Proc Cambridge Philos Soc 1935, 31:203-222.

75. Kass R: Bayes factors in practice. Statistican 1993, 42:551-560
76. Kass R, Raftery AE: Bayes factors. J Am Stat Assoc 1995, 90:773-795.

77. Drummond AJ, Rambaut A: BEAST: Bayesian evolutionary analysis by sampling trees. BMC Evol Biol 2007, 7:214.

78. Grandjean F: Observations sur les Oribates (39e série). Bull Mus Nat Hist natur 1959, 31:248-255.

79. Grandjean F: Sur un Acarien des îles Kerguelen, Podacarus auberti (Oribate). Mem Mus nat Hist nature, ser A Zool 1955, 8:109-150.

80. Weigmann G, Schulte $G$ : The evolution of the family Ameronothridae (Acari: Oribatei). I. Morphological aspects. Acarologia 1977, 19:161-166.

81. Grandjean F: Les organes respiratoires secondaires des Oribates (Acariens). Ann Soc Entomol France 1934, 103:109-146.

82. Norton RA, Alberti G: Porose integumental organs of oribatid mites (Acari, Oribatida): 3. Evolutionary and ecological aspects. Zoologica 1997, 146:115-143, (Stuttgart).

83. Behan-Pelletier VM, Eamer B, Clayton M: Dendroeremaeidae n. fam., from forest trees in western North America (Acari: Oribatida: Licneremaeoidea). Acarologia 2005, 45:321-339.

84. Woas S: Die phylogenetischen Entwicklungslinien der Höheren Oribatiden (Acari). I. Zur Monophylie der Poronota Grandjean, 1953. Andrias 1990, 7:91-168.

85. Behan-Pelletier VM: Ceratozetidae of the western North American arctic. Can Entomol 1985, 117:1287-1366.

86. Weigmann G: Anomalies of notogastral structures in poronotic oribatid mites (Oribatida: Poronota) interpreted as cryptic ancestral characters modulated by regulatory genes. Trends in Acarology - Proceedings XItth International Congress of Acarology Dordrecht: SpringerSabelöis MW, Bruin J 2009, 19-24.

87. Travé J, André HM, Taberly G, Bernini F: Les Acariens Oribates Agar \& SIALF Wavre Belgium 1996

88. Woas S: Acari: Oribatida. Amazonian Arachnida and Myriapoda Sofia, Moscow: Pensoft PublishersAdis J 2002, 21-291.

89. Shived U, Wallwork JA: An early Jurassic oribatid mite from southern Sweden. Geol Foren Stockh Forh 1978, 100:65-40.

90. Schaefer I, Norton RA, Scheu S, Maraun M: Arthropod colonization of land - Linking molecules and fossils in oribatid mites (Acari, Oribatida). Mol Phylogenet Evol

91. Smrž J: "Nymphes plissées" structure of the cuticle of juveniles of some oribatid mites (Acari: Oribatida). Eur J Entomol 2007, 104:619-629.

92. McPeek MA, Schrot AK, Brown JM: Adaptation to predators in a new community: swimming performance and predator avoidance in damselflies. Ecology 1996, 77:617-629.

93. Martins EP: Adaptation and the comparative method. Trends Ecol Evol 2000, 15:295-299.

94. Grant PR: Evolution in Darwin's finches: a review of a study on Isla Daphne Major in the Galápagos Archipelago. Zoology 2003, 106:255-259.

95. Wilkins AS: The evolution of developmental pathways Sunderland, MA: Sinauer 2002.

96. Carroll SB, Grenier JK, Weatherbee SD: From DNA to diversity: molecular genetics and the evolution of animal design Malden, MA: Blackwell Scientific, 22005.

97. Wiens JJ, Brandley MC, Reeder TW: Why does a trait evolve multiple times within clade? Repeated evolution of snakelike body form in squamate reptiles. Evolution 2006, 60:123-141.

98. Espinoza RE, Wiens JJ, Tracy CR: Recurrent evolution of herbivory in small, cold-climate lizards: breaking the ecophysiological rules of reptilian herbivory. Proc. Natl. Acad. Sci. USA 2004, 101:16819-16824.

99. Hunt GS, Colloff MJ, Dallwitz MJ, Walter DE: The oribatid mites of Australia: information retrieval and interactive identification to family, genus and species levels. CD-ROM. CSIRO Publishing, Melbourne 1998.

doi:10.1186/1471-2148-10-246

Cite this article as: Schäffer et al: Ancestral state reconstruction reveals multiple independent evolution of diagnostic morphological characters in the "Higher Oribatida" (Acari), conflicting with current classification schemes. BMC Evolutionary Biology 2010 10:246. 